Journal of Engineering and Applied Sciences 14 (13): 4303-4306, 2019

ISSN: 1816-949X

(C) Medwell Journals, 2019

\title{
Industrial Data Decomposition and Forecasting Using Discrete Wavelet Transform
}

\author{
${ }^{1}$ S. Al-Wadi and ${ }^{2}$ Abed H. Al-Slaihat \\ ${ }^{1}$ Department of Risk Management and Insurance, The University of Jordan, Jordan \\ ${ }^{2}$ Department of Hotel Management, The University of Jordan, Aqaba, Jordan
}

\begin{abstract}
Since, the industrial data plays significant element in any economic growth and these data have many factors that effect on its behavior. Therefore, in this study events of productivity of the extractive industry in Jordan will be explored and forecasted using some of traditional model which is (ARIMA Model and exponential model) compound with Orthogonal Wavelet Transform (OWT) in order to improve the forecasting accuracy. First, the series of dataset will be decomposed by OWT's functions in order to capture the significant affect based on detailed coefficients, then the smooth's series will be predicted using ARIMA Model, exponential model, OW+ARIMA Model and Exponential+OWT Model in order to improve the forecasting accuracy.
\end{abstract}

Key words: Orthogonal wavelet transform, ARIMA Model, exponential model, industry data, forecasting significant affect, behaviour

\section{INTRODUCTION}

Industry data tendencies are a interesting task. Some factors influence industry data performance, including economic conditions, general political events, and others. Though stock and futures traders trust strongly on numerous types of intelligent systems to make trading results to date their achievement has been limited (AbuMostafa and Atiya, 1996). Financial professionals find it problematic to make accurate forecasting, because industrial data is nonlinear and non-stationary. No agreement exists among specialists as to the effectiveness of predicting industrial data.

This study diverges from previous attempts at forecasting stock prices by proposing a method that uses the Wavelet Transforms (WT) combined with ARIMA, this process create a transparent architecture.

WT is a relatively new field in signal processing (Refenes et al., 1994). Wavelets are mathematical functions that decompose data into different frequency components, after which each component is studied with a resolution matched to its scale where a scale denotes a time horizon (Zhang et al., 2002). WT is closely related to the volatile and time varying characteristics of the real-world time series and is not limited by the stationary assumption (Popoola and Ahmad, 2006). WT decomposes a process into different scales, making it useful in distinguishing seasonality, revealing structural breaks and volatility clusters and identifying local and global dynamic properties of a process at specific timescales (Gencay et al., 2001). WT has been shown to be particularly useful in analyzing, modeling and predicting the behavior of financial instruments as diverse as stocks and exchange rates (Ramsey, 1999; Papagiannaki et al., 2005).

This study applies WT using the OWT functions which are (Haar, Daubechies, Coiflet and Symmelt) to decompose the industry time series then combine the approximation coefficients with ARIMA Model and exponential model in order to make improve the forecasting accuracy then select the best WT function in forecasting. Then finally, we compare the forecasting using the combined method with the forecasting using ARIMA Model directly and exponential model directly also. The framework combines several statistical methods and soft computing techniques using MATLAB Software and other statistical packages.

\section{MATERIALS AND METHODS}

WT is based on Fourier Transform (FT) which signifies any function as the sum of the sine and cosine functions. WT is simply a function of time t that obeys a basic rule, known as the wavelet admissibility condition (Gencay et al., 2002):

$$
\mathrm{c}_{\varphi}=\int_{0}^{\infty} \frac{[\varphi(\mathrm{f})]}{\mathrm{f}} \mathrm{df}<\infty
$$

where, , $(f)$ is the FT and a function of frequency $f$, of , $(t)$. WT is a mathematical equation that can be applied to

Corresponding Author: S. Al-Wadi, Department of Risk Management and Insurance, The University of Jordan, Aqaba, Jordan 


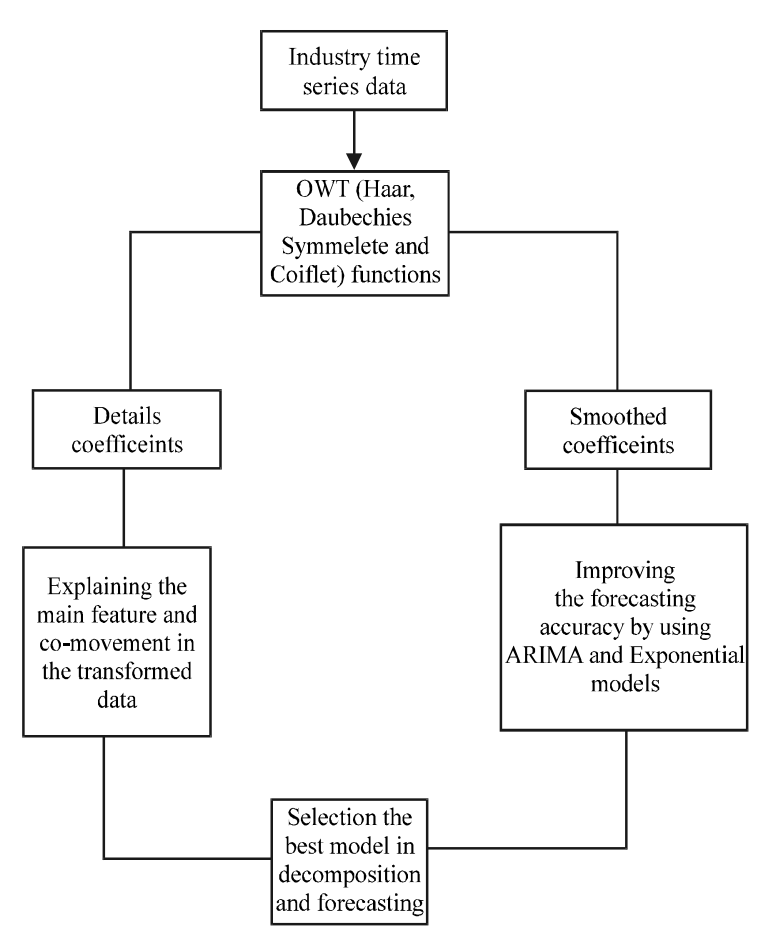

Fig. 1: Research framework

many applications, such as signal processing and image analysis. It was used to solve problems associated with the FT as they occur. This problem can take place when dealing with nonstationary data, or when dealing with data that are localized in time, space, or frequency. Based on on the normalization rules, we have two types of WT within a given function. Father wavelet show the smooth and low-frequency parts of a signal, and mother wavelets show the detailed and high-frequency components. In the following equations, (2a) represents the father wavelet and ( $2 b$ ) represents the mother wavelet, with $j=1, \ldots, J$ in the J-level wavelet decomposition (Ramsey, 1999):

$$
\begin{aligned}
\phi \mathrm{j}, \mathrm{k} & =2^{-\mathrm{j} / 2} \phi\left(\mathrm{t}-2^{\mathrm{j}} \mathrm{k} / 2^{\mathrm{j}}\right) \\
\varphi \mathrm{j}, \mathrm{k} & =2^{-\mathrm{j} / 2} \varphi\left(\mathrm{t}-2^{\mathrm{j}} \mathrm{k} / 2^{\mathrm{j}}\right)
\end{aligned}
$$

where, $\mathrm{J}$ denotes the maximum scale sustainable by the number of data points and the two types of wavelets stated above, namely father wavelets and mother wavelets and satisfies:

$$
\int \phi(t) d t=1 \text { and } \int \varphi(t) d t=0
$$

ARIMA Model: Application of nonlinear regression to price forecasting has not been reported, so far. Other approaches of econometric modeling are univariate time

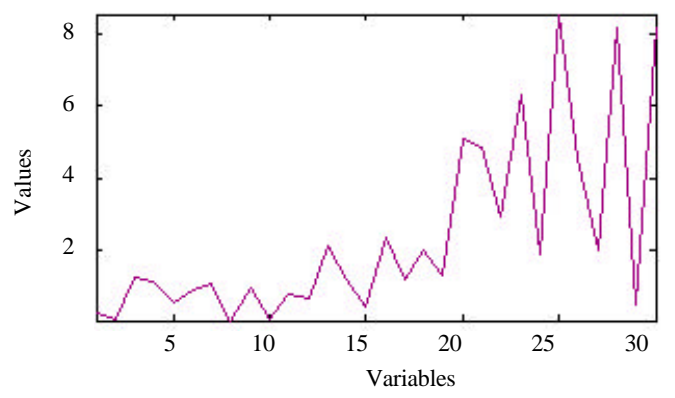

Fig. 2: The model building process

series methods like Auto Regressive Moving Average (ARMA) (Zadeh, 1994; Chen, 1996). ARMA is a suitable model for the stationary time series data, although, most of the software uses least square estimation which requires stationary. To overcome this problem and to allow ARMA Model to handle non-stationary data, the researchers investigate a special class for the nonstationary data. This model is called Auto-Regressive Integrated Moving Average (ARIMA). This idea is to separate a non-stationary series one or more times until the time series becomes stationary and then find the fit model. ARIMA Model has got very high attention in the scientific world. This model is popularized by George Box and Gwilym Jenkins in 1970s (Yoon et al., 1993). There are a huge number of ARIMA Models, generally there are ARIMA (p, q, d) where: p, order of Auto Regressive part (AR); d, degree of first differentiation (I) and q, order of the first moving part (MA). Note that, if there is no differencing been done $(\mathrm{d}=0)$, Then ARMA Model can be got from ARIMA Model. The general mathematical ARIMA Model can be defined as Chen (1996):

$$
\mathrm{W}_{\mathrm{t}}=\mu+\frac{\beta(v)}{\varepsilon(v)} \mathrm{a}_{\mathrm{t}}
$$

Where:

$$
\begin{aligned}
\mathrm{t}= & \text { Indexes time } \\
\mathrm{W}_{\mathrm{t}}= & \text { The response series } \mathrm{Y}_{\mathrm{t}} \text { or a difference of the } \\
& \text { response series } \\
\mu \quad= & \text { The mean term } \\
{ }_{v}= & \text { The backshift operator; that is } \mathrm{X}_{\mathrm{t}}=\mathrm{X}_{\mathrm{t}-1}
\end{aligned}
$$

$\therefore(v)=$ The autoregressive operator, represented as a polynomial in the backshift operator

$$
\varepsilon(v)=1-\varepsilon_{1}(v)-, \ldots,-\varepsilon_{\mathrm{p}} v^{\mathrm{p}}
$$

(.) $)$ : The moving-average operator, represented as a polynomial in the backshift operator:

$$
\beta(v)=1-\beta_{1}(v)-, \ldots,-\beta_{\mathrm{p}} v^{\mathrm{p}}
$$


$a_{t}$, the independent disturbance, also called the random error. The model building process involves the following steps; model identification, model parameter estimation, model diagnostics and forecasting.

\section{RESULTS AND DISCUSSION}

The daily price index of Amman Stock Exchange (ASE) from 2005-2011 has been selected as the statistical population. The aim of this study is to explore and forecast the productivity of the extractive industry in Jordan between 2005 and 2011 using some traditional models such as ARIMA Model and exponential model compound with compound with Orthogonal Wavelet Transform (OWT) to improve the accuracy of forecasting.

There are many external and internal factors and conditions at social, economic and political aspects negatively influencing the industry sector in Jordan in the first decade of the 21 st century. The political instability, especially which the region has experienced, since, the American invasion of Iraq in 2003 has had serious consequences on the Jordanian industries by significantly reducing and blocking the accessibility of local-made products to the markets of the neighboring countries, particularly Iraq that was Jordan's primary trade partner and a major market for Jordanian exports. For example, Jordan exported $22 \%$ of its total domestic exports to Iraq in 2001. This percentage had declined to almost $12 \%$ in 2006 . This change shows significant reduction in Jordanian exports to Iraq. Additionally, Iraq's war significantly contributed to inflation in Jordan by rising food price, rising fuel price and pricing real estate prices. This may refer to cutting Jordan off from the subsidized oil that it had been receiving from Iraq. Moreover, the regional instability had has hesitation by Foreign firms to come to Jordan for investment.

In light of Iraq's was in 2003 and global economic crisis in 2008, Jordan started implementing new and hard economic policies focusing mainly on tax reform within the framework of the economy restructuring programs by expanding the base of taxable goods and services. This particular tax policy negatively influences the industrial sectors in different pictures. First, tax reform program rises inflation and depresses the purchasing power of the existing capital stock and canlead to lower consumer spending. The tax reform can increase the cost and therefore, crease the cost of products and activities. This policy also, negatively influence the competitive advantage of goods and products.
Table 1: Forecasting results.

\begin{tabular}{lccc}
\hline WT & ARIMA+WT & ARIMA directly & \\
Exponential results directly & & \\
\hline Haar & 7.42 & 15.50 & 6.4 \\
Db & 2.43 & 11.67 & 7.9 \\
Symm & 3.5 & 12.34 & 4.8 \\
Coef & 3.67 & 12.11 & 6.9 \\
\hline
\end{tabular}

In addition, to the effect of global economic crisis started in 2008, tax reform also, negatively influences the Foreign investment by decreasing the attractiveness of environmental investment in the country. According to, Jordan Central Bank, the net Foreign investment flow had experienced dramatically from 893 million $\mathrm{D}$ in the first half of 2008-310 million J for the same period of 2009 . Since, 2006 net Foreign direct investment inflows had declined dramatically from over $\$ 3.5$ billon to under $\$ 2$ billion. The previous conditions combined also played a key role in declining Jordan's export to outside markets. For example, US imports from Jordan had declined, since, its peak at just over $\$ 1.4$ billion in 2006 . It had hovered at around $\$ 1$ billion, since, the global recession in 2008 . According to, the Department of Statistics, the number of closed manufacturing factories at Jordan's qualified industrial zones was 33 out of 110 factories between 2007 and 2010. Based on what has been mentioned above, the industrial sector in Jordan is more likely to face more challenges and problems and then reduction in light of continuing the political instability in the regions, especially, in Iraq and Syria that are considered Jordan's major trade partners.

In Table 1, appear comparisons between ARIMA and ARIMA-WT Models for mentioned dataset where the accuracy criteria; RMSE as indicated from Table 1, we found that $\operatorname{ARIMA}(2,2,1)$ with daubechies WT is better than ARIMA $(0,1,2)$ based on the directly model because it has lower RMSE value (Abramovich et al., 2002; Engle, 2001; Marmer, 2008; Parasuraman and Elshorbagy, 2005).

\section{CONCLUSION}

The goal of this study is to show estimating and forecasting of closed price stock market data. ARIMA Model is the most general way of forecasting since there is no need for any assumptions and it is not limited to specific type of pattern. These models can be fitted to any set of time series data (Stationary or non-stationary) by estimating the parameters $\mathrm{p}, \mathrm{d}$ and $\mathrm{q}$ to be suitable with the required data set. In this study, firstly, the dataset is modelled based on wavelet method. Secondly, we compared ARIMA, exponential and ARIMA+Wavelet model. Then the researchers were found that ARIMA+WT is a suitable model. 


\section{ACKNOWLEDGEMENT}

The researchers would like to thank Dr. Malek-Aljamaliah an assistant professor at Tourism Management Department, University of Jordan/Aqaba Branch for his cooperation and help with editing the manuscript. The researchers would like also to grateful to the anonymous reviewers for their insightful comments which have improved the quality of the study.

\section{REFERENCES}

Abramovich, F., P. Besbeas and T. Sapatinas, 2002. Empirical bayes approach to block wavelet function estimation. Comput. Stat. Data Anal., 39: 435-451.

Abu-Mostafa, Y.S. and A.F. Atiya, 1996. Introduction to financial forecasting. Applied Intell., 6: 205-213.

Chen, S.M., 1996. Forecasting enrollments based on fuzzy time series. Fuzzy Sets Syst., 81: 311-319.

Engle, R., 2001. GARCH 101: The use of ARCH/GARCH models in applied econometrics. J. Econ. Perspect., 15: 157-168.

Gencay, R., F. Selcuk and B. Whitcher, 2001. Differentiating intraday seasonalities through wavelet multi-scaling. Physica A. Stat. Mech. Appl., 289: 543-556.

Gencay, R., F. Selcuk and B. Whitcher, 2002. An Introduction to Wavelets and Other Filtering Methods in Finance and Economics Academic Press, New York.

Marmer, V., 2008. Nonlinearity, nonstationarity and spurious forecasts. J. Econ., 142: 1-27.
Papagiannaki, K., N. Taft, Z.L. Zhang and C. Diot, 2005. Long-term forecasting of Internet backbone traffic. IEEE. Trans. Neural Networks, 16: 1110-1124.

Parasuraman, K. and A. Elshorbagy, 2005. Wavelet networks: An alternative to classical neural networks. Proceedings of the 2005 IEEE International Joint Conference on Neural Networks Vol. 5, July 31-August 4, 2005, IEEE, Montreal, Canada, pp: 2674-2679.

Popoola, A. and K. Ahmad, 2006. Testing the suitability of wavelet preprocessing for TSK fuzzy models. Proceedings of the 2006 IEEE International Conference on Fuzzy Systems, July 16-21, 2006, IEEE, Vancouver, Canada, pp: 1305-1309.

Ramsey, J.B., 1999. The contribution of wavelets to the analysis of economic and financial data. Philos. Trans. Royal Soc. London Ser. A. Math. Phys. Eng. Sci., 357: 2593-2606.

Refenes, A.N., A. Zapranis and G. Francis, 1994. Stock performance modeling using neural networks: A comparative study with regression models Neural Networks, 7: 375-388.

Yoon, Y., G. Swales Jr and T.M. Margavio, 1993. A comparison of discriminant analysis versus artificial neural networks. J. Oper. Res. Soc., 44: $51-60$.

Zadeh, L.A., 1994. The role of fuzzy logic in modeling, identification and control. Model. Identif. Control, 15: 191-203.

Zhang, Y.Q., S. Akkaladevi, G. Vachtsevanos and T.Y. Lin, 2002. Granular neural web agents for stock prediction. Soft Comput., 6: 406-413. 